\title{
1 Numerical simulations of pressure buildup and salt precipitation \\ 2 during carbon dioxide storage in saline aquifers
}

3

4 Qingliang Meng ${ }^{\mathrm{a}, *}, \mathrm{Xi} \mathrm{Jiang}^{\mathrm{b}}{ }^{\mathrm{b}}$, Didi $\mathrm{Li}^{\mathrm{c}}$ and Qiyuan Xie

$5 \quad{ }^{a}$ Beijing Institute of Space Mechanics \& Electricity, Beijing 100094, China

$6 \quad{ }^{\mathrm{b}}$ Engineering Department, Lancaster University, Lancaster LA1 4YR, United Kingdom

$7 \quad{ }^{\mathrm{c}}$ Department of Safety Science Engineering \& State Key Laboratory of Fire Science,

8 University of Science and Technology of China, Hefei, Anhui 230026, China

$9 \quad *$ Corresponding author. Email: qlmeng@mail.ustc.edu.cn

11 Abstract

The storage of large amounts of carbon dioxide $\left(\mathrm{CO}_{2}\right)$ captured from fossil fuel fired power plants in deep saline aquifers can be an effective and promising measure for reducing the emissions of greenhouse gases. Massive $\mathrm{CO}_{2}$ injection into saline aquifers may cause multi-scale phenomena such as pressure buildup in a large scale, $\mathrm{CO}_{2}$ plume evolution in a medium scale and salt precipitation in a small scale. In this study, three-dimensional

17 simulations are performed to investigate the propagation of pressure and the impact of salt precipitation on the process of large scale $\mathrm{CO}_{2}$ injection into the saline aquifers. Apart from the different scales of the processes, the numerical results show clearly different behaviours of the

20 pressure changes in saline aquifers with different boundaries. Different types of salt 
21 precipitation occur adjacent to the injection well, presenting distinct impacts on the fluid flow.

22 Affected by salt precipitation, the porosity and permeability are reduced, leading to declined

23 transportation and degraded injectivity with different boundary conditions. The interplay

24 between pressure buildup and solid saturation is compared in saline aquifers with different

25 boundary conditions.

26

27 Keywords: $\mathrm{CO}_{2}$ storage, Pressure buildup, Salt precipitation, $\mathrm{CO}_{2}$ plume, Numerical

28 simulations

29 
31

\begin{tabular}{|c|c|}
\hline & \\
\hline$d$ & diffusivity \\
\hline D & distance between meshes $m$ and $n$ \\
\hline g & gravitational acceleration \\
\hline $\mathbf{k}$ & permeability tensor \\
\hline$k_{r g}$ & the relative permeability of $\mathrm{CO}_{2}$ \\
\hline$k_{r 1}$ & the relative permeability of brine \\
\hline $\mathbf{n}$ & normal vector \\
\hline$P$ & pressure \\
\hline $\mathbf{q}$ & Darcy flux \\
\hline$S$ & saturation \\
\hline$t$ & time \\
\hline$T$ & temperature \\
\hline$V$ & volume \\
\hline$X$ & mass fraction \\
\hline
\end{tabular}

$x, y, z \quad$ Cartesian coordinates 
Greek symbols

\begin{tabular}{|c|c|}
\hline$\Gamma$ & area \\
\hline$\mu$ & dynamic viscosity \\
\hline$\rho$ & density \\
\hline$\Sigma$ & summation \\
\hline$\tau$ & tortuosity \\
\hline$\phi$ & porosity \\
\hline$\nabla$ & gradient operator \\
\hline
\end{tabular}

Subscripts/superscripts

c capillary, critical

$i, j, m, n$ index

s $\quad$ solid

$\alpha, \beta \quad$ fluid phase

32 


\section{Introduction}

34 Carbon dioxide storage in deep saline aquifers is potentially the most promising method for

35 massively reducing the ever increasing amount of $\mathrm{CO}_{2}$ in the global atmospheric environment

36 because of combustion utilization of fossil fuels [1-3]. Massive $\mathrm{CO}_{2}$ injection into the saline

37 aquifers may cause multi-scale spatial phenomena, including pressure buildup occurred in a

38 large scale [4-6], $\mathrm{CO}_{2}$ plume in a medium size $[4,5]$ and the distribution of precipitation in a

39 small dimension [7]. When large volumes of $\mathrm{CO}_{2}$ are injected into saline aquifers, pressure

40 buildup may be produced which can quickly propagate in a large space. At the temperature and

41 pressure conditions for $\mathrm{CO}_{2}$ storage, the injected $\mathrm{CO}_{2}$ will tend to accumulate at the top of

42 reservoir and spread out along the top caprock, as schematically shown in Fig. 1(a). Meanwhile,

43 the injection of dry supercritical $\mathrm{CO}_{2}$ will displace the resident brine immiscibly, combined

44 with the evaporation of water, which may eventually cause the aqueous phase dry-out and salt

45 precipitation near the injection well [7-14]. The spatial size of precipitation region is just a

46 small fraction of the plume. These phenomena are of great importance to the safety of $\mathrm{CO}_{2}$

47 storage. On the one hand, excessive pressurization may cause a series of problems, involving

48 the caprock fracture, the pollution of shallow groundwater resources, and the seismicity [15-18].

49 On the other hand, salt precipitation may lead to salt blockage near the injection well, which

50 would obstruct the transportation of $\mathrm{CO}_{2}$ and the propagation of pressure to the far filed [7, 8].

51 Therefore, predicting the propagation of pressure and the impact of salt precipitation on

52 injectivity is crucial to the security of $\mathrm{CO}_{2}$ storage in saline aquifers. 


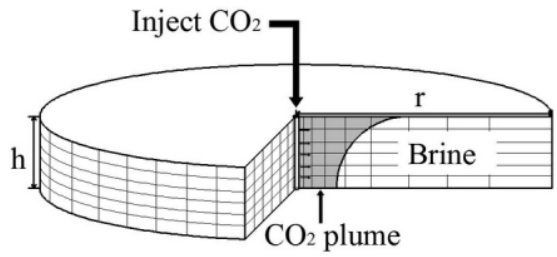

(a)

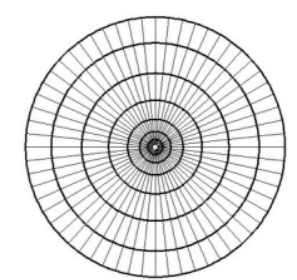

(b)

54 Fig. 1. Schematic representation of (a) $\mathrm{CO}_{2}$ injection into an aquifer via a vertical well and (b) top view.

The pressure buildup during $\mathrm{CO}_{2}$ injection into saline aquifers has been the focus of research by a number of theoretical analyses and numerical simulations. In terms of the theoretical analyses, several simple semi-analytical methods using Buckley-Leverett equation are used to study the distribution of pressure, which describe the one-dimensional immiscible flow in the absence of compression of rock pores and brine and capillary pressure [19-21]. Mathias et al. [4] improved the Buckley-Leverett method by incorporating the compressibility of rock and brine to study the pressure buildup during $\mathrm{CO}_{2}$ injection into a closed saline aquifer. Zhou et al. [6] developed a quick assessment method of $\mathrm{CO}_{2}$ storage capacity due to the formation and fluid compressibility, with assumptions that pressure buildup is spatially uniform and independent of formation permeability. Although these theoretical analyses may efficiently predict the pressure changes in some cases, detailed numerical simulations of carbon storage to calculate the

67 pressure buildup including the spatial and temporal distributions are needed. For numerical studies, the important physical phenomena of pressure buildup are observed. Nonlinear

69 behaviours of pressure change near wellbore during $\mathrm{CO}_{2}$ injection into saline aquifers are 70 observed [22]. Large-scale $\mathrm{CO}_{2}$ injection could cause groundwater pressure perturbation and 71 hydrological impact on groundwater resources [5, 17, 23, 24]. If the pressure buildup is above a 
Protection Agency, stating that the maximum pressure must not exceed $90 \%$ of the fracture pressure in the injection zone [25]. Coupled reservoir geomechanical analyses are performed to check the fracture pressures by numerical simulations [26, 27]. Numerical simulations and optimization schemes are increasingly used to investigate this phenomenon, e.g. [28]. Optimization and parallel algorithms are also available to improve computation performance, e.g. [29-32]. The previous studies indicate that the pressure buildup in the injection zone is crucial to the security of $\mathrm{CO}_{2}$ storage.

The process of salt precipitation has also been investigated by several theoretical analyses,

81 experimental studies and numerical simulations. For theoretical analyses, Zeidouni et al. [10] developed a graphical method to determine the location of the front of solid salt. However, their results neglect the effects of the capillary pressure and the gravitational force. In addition their results are only applicable to a very simplified one-dimensional situation. For experimental studies, the reduction of permeability induced by drying of brine in porous media is studied for different rocks and salt contents [33]. A lab-on-a-chip approach is developed to study the pore-scale salt precipitation dynamics during $\mathrm{CO}_{2}$ injection into saline aquifers [34]. Although experimental studies can provide first-hand results, detailed measurements are always difficult especially when information on flow quantities over a broad range of time and length scales is needed. In numerical studies, several researchers have shown that salt precipitates

91 preferentially near the injection well as resident saline water is evaporated by injected $\mathrm{CO}_{2}[7,8$, 
94 permeability. Pruess and Müller [7] carried out one- and two-dimensional studies to predict salt

95 precipitation and to understand the influencing factors for this process. Kim et al. [8] pointed

96 out that there are two types of precipitation at different injection rates using two-dimensional

97 simulations, which are characterized by different level of salt precipitation near the well. Their

98 results suggest that great pressure buildup would occur near the lower portion of the injection

99 well in some cases. These previous studies indicate that salt precipitation could cause reduction

100 of aquifer porosity and permeability near the well and thus deterioration of injectivity.

101 Although some understandings on the impacts of pressure buildup and salt precipitation of

$102 \mathrm{CO}_{2}$ injection into the saline aquifers have been obtained, more studies are needed to

103 understand the interplay between pressure buildup and salt precipitation. In previous numerical

104 studies of salt precipitation in saline aquifers, the injection period is short and the injection rate

105 was low, which does not meet the requirements of long-term and large-scale $\mathrm{CO}_{2}$ storage. In the

106 meantime, comparisons of the two phenomena in storage systems with different boundary

107 conditions, namely the closed, open and semi-closed systems, are important but have not been

108 investigated systematically.

109 In this study, the distributions of pressure buildup and salt precipitation, the specific

110 processes and the impacts of solid precipitation on the long-term injection in the three storage

111 systems are investigated by three-dimensional (3D) simulations. In the following, the

112 governing equations together with the initial and boundary conditions used in the simulations

113 are presented first, followed by numerical results and discussions of the results for the three

114 systems investigated. Finally, some conclusions are drawn. 


\section{Modelling and mathematical formulation}

116

\subsection{Physical problem and computational domain}

The physical problem is $\mathrm{CO}_{2}$ injection and propagation, via a vertical well, into saline aquifers, as indicated in Fig. 1(a). The storage formation, located at a depth of approximate $1200 \mathrm{~m}$ below the ground surface, is $100 \mathrm{~m}$ thick with a radius of $40 \mathrm{~km}$ for the closed and semi-closed systems. The lateral extent of computation model for the open system is $100 \mathrm{~km}$, which ensures that the lateral boundary could have a minimal effect on the simulation results.

\subsection{Governing Equations}

The governing equations for the fluid flows of multiphase and multicomponent fluid mixtures in porous media are used to describe $\mathrm{CO}_{2}$ geological storage in saline aquifers [3], which are similar to those for oil, water, and gas flows through porous media. For isothermal problems, only the mass conservation equations for $\mathrm{CO}_{2}$, water and salt are considered. The integral form of the mass equations for an individual ith species or component is given as [38]:

$$
\frac{\partial}{\partial t} \int_{V_{n}} \phi \sum_{\alpha}\left(\rho_{\alpha} S_{\alpha} X_{i}^{\alpha}\right) d V_{n}+\int_{\Gamma_{\mathbf{n}}} \sum_{\alpha}\left(\rho_{\alpha} X_{i}^{\alpha} \mathbf{q}_{\alpha}\right) \cdot \mathbf{n} d \Gamma_{\mathbf{n}}-\int_{\Gamma_{\mathbf{n}}} \sum_{\alpha}\left(\phi S_{\alpha} \tau_{\alpha} d_{i}^{\alpha} \rho_{\alpha} \nabla X_{i}^{\alpha}\right) \cdot \mathbf{n} d \Gamma_{\mathbf{n}}=\int_{V_{n}} Q_{i} d V_{n}
$$

where $\mathbf{n}$ is the normal vector on the surface element $d \Gamma_{n}$ (assumed pointing inward into the mesh $n$ ). Eq. (1) is constructed by the balance of four terms representing all the possible mechanisms for mass transfer, which are the time rate of change of mass at a fixed point (or the local derivative or storage term), convective and diffusive transports, and source/sink term of mass respectively. $\mathbf{q}_{\alpha}$ can be defined by Darcy's law [39]:

$$
\mathbf{q}_{\alpha}=-\frac{\boldsymbol{k} k_{r \alpha}}{\mu_{\alpha}}\left(\nabla P_{\alpha}+\rho_{\alpha} \mathbf{g} \nabla z\right)
$$



the fluid momentum balance in creeping flow through porous media. The law is only valid for steady, slow viscous flow, which can be derived from the Navier-Stokes momentum equations. studied here. They are a coupled nonlinear system involving the geo-mechanical effects such as permeability and porosity of the solid rock matrix, multi-phase fluid properties like density and

141 viscosity, which all affect the flow and transport behaviours. In order to close this mathematical problem, constitutive relationships and supplementary constraints for saturations, component compositions and pressures are needed [3]. needed. In general, the two-phase characteristic curves are a function of the pore structure,

148 phase saturation, surface tension, contact angle, and hysteresis [38].

149 The relative permeabilities of brine and $\mathrm{CO}_{2}$ are calculated as follows:

$$
k_{r l}=\sqrt{S^{*}}\left\{1-\left(1-\left[S^{*}\right]^{1 / \lambda}\right)^{\lambda}\right\}^{2}
$$

$$
k_{r g}=(1-\hat{S})^{2}\left(1-\hat{S}^{2}\right)
$$

$$
S^{*}=\left(S_{l}-S_{l r}\right) /\left(1-S_{l r}\right)
$$

$$
\hat{S}=\left(S_{l}-S_{l r}\right) /\left(1-S_{l r}-S_{g r}\right)
$$


saturation, while $S_{l r}$ and $S_{g r}$ are the irreducible liquid and gas saturations, respectively. Eq. (3)

156 for liquid is developed by van Genuchten [40]; eq. (4) for gas is due to Corey [41]. The formation for capillary pressure is given by van Genuchten [40]:

158

$$
P_{c, \alpha \beta}=-P_{0}\left(\left[S^{*}\right]^{-1 / \lambda}-1\right)^{1-\lambda}
$$

159 where $P_{0}$ is the strength coefficient, and $\lambda$ is a parameter depending on pore geometry.

160 The difference of pressures between the two phases satisfies the following relation [39]:

$$
P_{\beta}=P_{\alpha}+P_{c, \alpha \beta}
$$

Eq. (8) shows that the fluid pressure in phase $\beta$ is the sum of the gas phase pressure $P_{\alpha}$ and the capillary pressure $P_{c, \alpha \beta}$.

The evaporation model for $\mathrm{H}_{2} \mathrm{O}$ partitioning into $\mathrm{CO}_{2}$-rich phase is given by Spycher and

165 Pruess model [42], which gives the mutual solubilities of $\mathrm{CO}_{2}$ and $\mathrm{H}_{2} \mathrm{O}$ in a non-iterative manner.

167 The salt precipitation due to the evaporation of injected $\mathrm{CO}_{2}$ affects the fluid flows of gas and aqueous phases by changing the porosity and permeability of the formations. The solid salt occupies a fraction of the volume of the pores, which will lead to the decrease of space available for gas and aqueous phases. In this study, the solid salt is assumed to be immobile. Similar to

171 the saturations of gas and aqueous phases, solid saturation is defined to describe the fraction of pore space occupied by salt precipitation.

173 In modelling the interplay between the two-phase flow and salt precipitation, it is important 174 to specify the relationship between porosity and permeability. The underground formations 
contain different sizes of pores. Some precipitation can occur in the large pores, in which the permeability may not change much; others are found in the small pores, in which the permeability may decrease dramatically. The porosity-permeability relationship has been discussed by many investigators [14, 43, 44], whose results differ considerably from each other due to the complexity of the problem.

A tubes-in-series model is used to describe the permeability change due to the solid precipitation [44]. The model is composed of a series of parallel tubes with larger and smaller radii. The axes of the tubes are parallel to the fluid flows. The flow channels contain a great number of pore throats, hence even small changes in porosity may lead to dramatic permeability change due to the blockage of the pore throats. This permeability may be reduced to zero at a finite porosity, which can be defined as the "critical porosity". In this study, the permeability decreases to zero when the porosity is reduced to $80 \%$ of its original value, i.e., when the solid saturation reaches 0.20 .

\subsection{Boundary and initial conditions}

In terms of physical boundaries, the storage systems can be theoretically divided into three categories: (i) a closed system in which all the boundaries are impervious; (ii) an open system whose lateral boundaries are open so that the native brine can flow out; and (iii) a semi-closed system in which the lateral boundaries are impervious, while the storage formation is vertically bounded by sealing units with low permeability $[6,15]$. For a closed system, the storage depends on the compressibility of the formation fluids and rock material as well as the dissolution rate of $\mathrm{CO}_{2}$, which can provide expanded volumes available for storing the injected $\mathrm{CO}_{2}[4,16]$. For an open system, the injected $\mathrm{CO}_{2}$ displaces the brine laterally and is stored in 

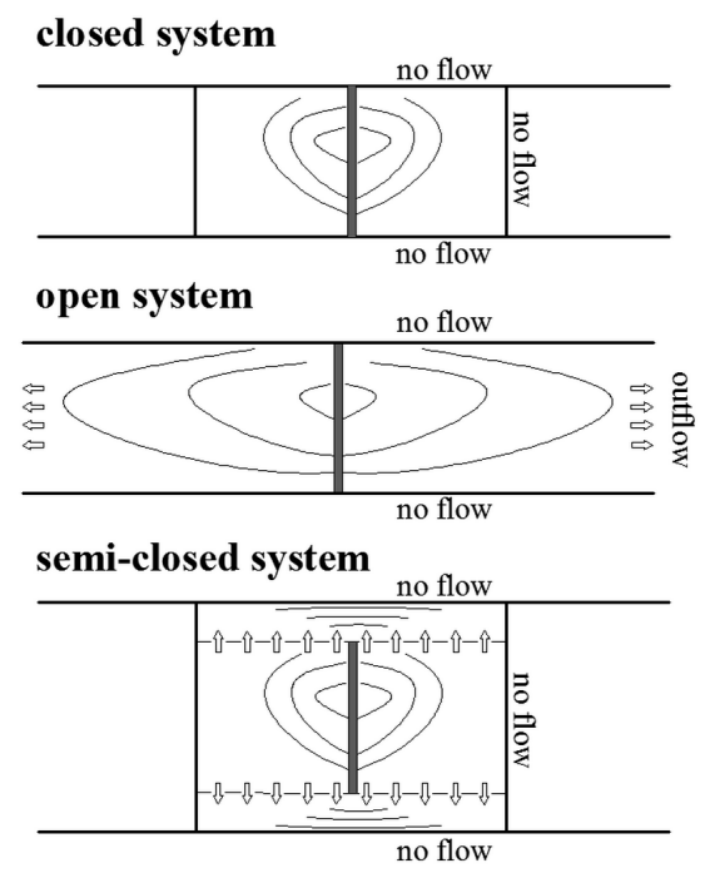

201 Fig. 2. Schematic representation of boundary conditions for the three storage systems: (a) open system, (b) closed system, and (c) semi-closed system.

All the boundaries for the closed and semi-closed systems are assumed to be impermeable to

204 both supercritical $\mathrm{CO}_{2}$ and brine except the wellbore boundary. For the open system, the volumes of grid blocks at the lateral boundary are assigned with an extremely large numerical value of $10^{50} \mathrm{~m}^{3}$, thereby imposing a constant pressure condition at the far field. The top and bottom boundaries are also impervious. For the semi-closed system, two sealing formations with $60 \mathrm{~m}$ thick each are located at the top and the bottom of the storage system. The boundary conditions for the three storage systems are shown in Fig. 2.

Tab. 1. Hydrogeological properties of the storage formation. 


\section{Initial conditions}

\begin{tabular}{ll}
\hline Temperature & $T=45^{\circ} \mathrm{C}$ \\
Salinity & $X_{s}=0.15$ \\
Pressure & $P_{\text {ini }} \approx 120-131$ bars \\
Dissolved $\mathrm{CO}_{2}$ concentration & $X_{1}=0$. \\
\hline
\end{tabular}

\section{Formation properties}

\begin{tabular}{ll}
\hline Horizontal permeability & $k_{h}=10^{-12} \mathrm{~m}^{2}$ \\
Vertical permeability & $k_{v}=10^{-12} \mathrm{~m}^{2}$ \\
Porosity & $\phi=0.12$ \\
Pore compressibility & $D=4.5 \times 10^{-10} \mathrm{~Pa}^{-1}$ \\
\hline
\end{tabular}

211 Tab. 1 lists the assigned values of parameters used in this study, which are the typical

212 conditions suitable for $\mathrm{CO}_{2}$ storage. The formations are initially fully brine-saturated with the

213 hydrostatic pressure distributing over the depths of the formations. The injection rate and

214 injection period in the three systems are the same, which are $100 \mathrm{~kg} / \mathrm{s}$ and 30 years, respectively.

215 In order to examine the effect of the injection rate, a rate of $50 \mathrm{~kg} / \mathrm{s}$ with injection period of 60

216 years is also considered for the closed system. Temperature is fixed at $45^{\circ} \mathrm{C}$ throughout the

217 simulations, representing an isothermal condition for the simulations considered here.

\section{$218 \quad 2.4$ Numerical methods}

219 The mass equations are discretized temporally using an implicit finite difference scheme and 
in space using an integral finite difference method as follows:

221

$$
\begin{aligned}
& {\left[\phi_{n}^{t+\Delta t} \sum_{\alpha}\left(\rho_{n, \alpha}^{t+\Delta t} S_{n, \alpha}^{t+\Delta t} X_{n, i}^{\alpha, t+\Delta t}\right)-\phi_{n}^{t} \sum_{\alpha}\left(\rho_{n, \alpha}^{t} S_{n, \alpha}^{t} X_{n, i}^{\alpha, t}\right)\right] \cdot \frac{V_{n}}{\Delta t}+} \\
& \sum_{m}\left\{\left[\left\{\sum_{\alpha}\left(\rho_{\alpha, n m}^{t+\Delta t} X_{i, n m}^{\alpha, t+\Delta t} q_{\alpha, n m}^{t+\Delta t}\right)\right] \cdot \Gamma_{n m}\right\}-\right. \\
& \sum_{m}\left\langle\left\{\left\{\sum_{\alpha}\left[\phi_{n m}^{t+\Delta t} S_{\alpha, n m}^{t+\Delta t} \tau_{\alpha, n m}^{t+\Delta t} d_{i, n m}^{t+\Delta t} \rho_{\alpha, n m}^{t+\Delta t}\left(X_{i, n}^{\alpha, t+\Delta t}-X_{i, m}^{\alpha, t+\Delta t}\right) / D_{n m}\right]\right\} \cdot \Gamma_{n m}\right\rangle\right. \\
& =Q_{n, i}^{t} \cdot V_{n}
\end{aligned}
$$
the values at the new time step.
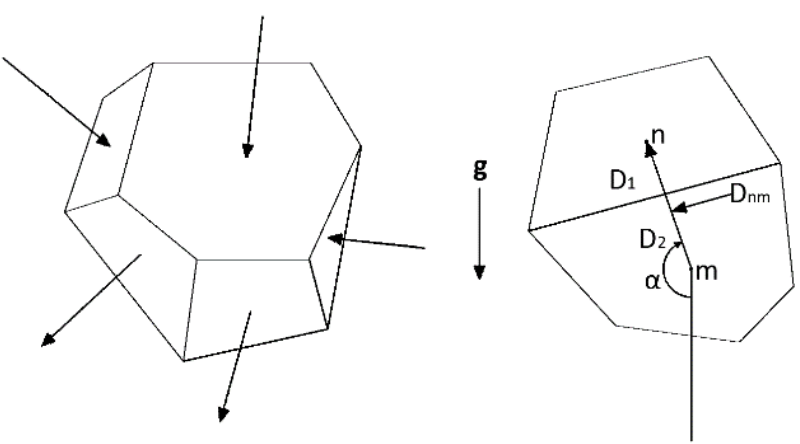

Fig. 3. Spatial discretization considered in this study.

The Darcy's law is discretized in the following way:

$$
q_{n m}^{t+\Delta t}=-\left(\frac{k}{\mu}\right)_{n m}^{t+\Delta t}\left(\frac{P_{n}^{t+\Delta t}-P_{m}^{t+\Delta t}}{D_{n m}}-\rho_{n m}^{t+\Delta t} g \cos \alpha\right)
$$

where $\alpha$ is the intersection angle between gravitational acceleration and the line segment from mesh $\mathrm{m}$ to $\mathrm{n}$ with rotation direction from $\mathrm{g}$ to the line segment clockwise as indicated in Fig. 3.

$$
\cos \alpha=\frac{Z_{2}-Z_{1}}{D_{1}+D_{2}}
$$

231 The variables in Eq. (9) - (10) on the interface are treated by distances harmonic averages 
method, given by,

$$
f_{\alpha, n m}^{t+\Delta t}=\frac{D_{1} f_{\alpha, m}^{t+\Delta t}+D_{2} f_{\alpha, n}^{t+\Delta t}}{D_{1}+D_{2}}
$$

$$
f=\left\{\phi, S_{\alpha}, \tau_{\alpha}, d_{i}^{\alpha}, \rho_{\alpha}, h_{\alpha}, \lambda\right\}
$$

235 A set of coupled nonlinear equations are obtained from Eq. (9)-(10). The compressed sparse 236 row (CSR) format is adopted to store the sparse matrix linearized by the Newton-Raphson 237 iteration $[28,45]$. Nonzero elements of the matrix are stored in CSR format. Afterwards, the 238 obtained system of linear equations is solved by parallel algorithm. In order to perform parallel 239 simulations, domain decomposition method is used. The computational domain is decomposed 240 into a number of subdomains. A global solution is formed through the local solutions on the 241 subdomains. Solutions for subdomains can be sought simultaneously. In order to achieve better 242 computational performance, each processor is assigned to the roughly the same number of 243 meshes.

244 In order to track the process accurately and effectively, the temporal differencing is based on 245 an automatic scheme, by changing the time steps according to the variations of solutions between adjacent time steps.

Processor $0 \quad$ Processor 1

\begin{tabular}{|c|c|c|c|}
\hline 1 & 2 & 3 & 4 \\
\hline 5 & 6 & 7 & 8 \\
\hline 9 & 10 & 11 & 12 \\
\hline 13 & 14 & 15 & 16 \\
\hline
\end{tabular}

Processor $2 \quad$ Processor 3 
249 Fig. 4 shows a scheme for partitioning a sample domain with 16 meshes into four parts. Grids

250 are assigned to four different processors and reordered to a local index ordering at each

251 processor. The partitioned meshes are stored in each processor's update set. The update set is

252 further divided into two subsets: internal and border. The solutions of elements in the internal

253 subset only use the information on the current processor. The border subset includes grids that

254 would require values from the other processors to be updated. An external set stores the meshes

255 that are not in the current processor, which are needed to update the grids in the border set. Tab.

2562 shows an example of the domain partitioning and local numbering.

257 Tab. 2. Example of domain partitioning and local numbering.

\begin{tabular}{|c|c|c|c|c|}
\hline \multirow{2}{*}{ Processor } & & \multicolumn{2}{|l|}{ update } & \multirow{2}{*}{ external } \\
\hline & & internal & border & \\
\hline & Mesh & 1 & $2,5,6$ & $3,7,9,10$ \\
\hline \multicolumn{5}{|l|}{ Processor 0} \\
\hline & Local Numbering & 1 & $2,3,4$ & $5,6,7,8$ \\
\hline & Mesh & 4 & $3,7,8$ & $2,6,11,12$ \\
\hline \multicolumn{5}{|l|}{ Processor 1} \\
\hline & Local Numbering & 1 & $2,3,4$ & $5,6,7,8$ \\
\hline & Mesh & 13 & $9,10,14$ & $5,6,11,15$ \\
\hline \multicolumn{5}{|l|}{ Processor 2} \\
\hline & Local Numbering & 1 & $2,3,4$ & $5,6,7,8$ \\
\hline Processor 3 & Mesh & 16 & $11,12,15$ & $7,8,10,14$ \\
\hline
\end{tabular}


258 Communication between processors is an essential task of the parallel algorithm. Global

259 communication is used to contribute grid blocks to all processors and check the convergence. In

260 order to solve the linear equation system, communications between adjacent processors and

261 linear solver routine are needed. When the meshes are in the border subset, exchange of data

262 corresponding to the external set is performed.

$263 \quad 2.5$ Grid dependence tests

264 In order to obtain a better understanding on how the grid resolution affects numerical

265 solutions, grid dependence is examined for the 3D closed system. Four different sets of grids in

266 the range of 1.5-12 million are used to evaluate the dependence of the results on the grid

267 number and determine the optimum number of grids, as shown in Fig. 5. The plots show the

268 radial distributions of pressure buildup (compared with the initial pressure) and solid saturation

269 at 10 days and 100 days along the top aquifer. It is evident that the optimal number of grids is 6

270 million by considering the computational accuracy and the efficiency. 


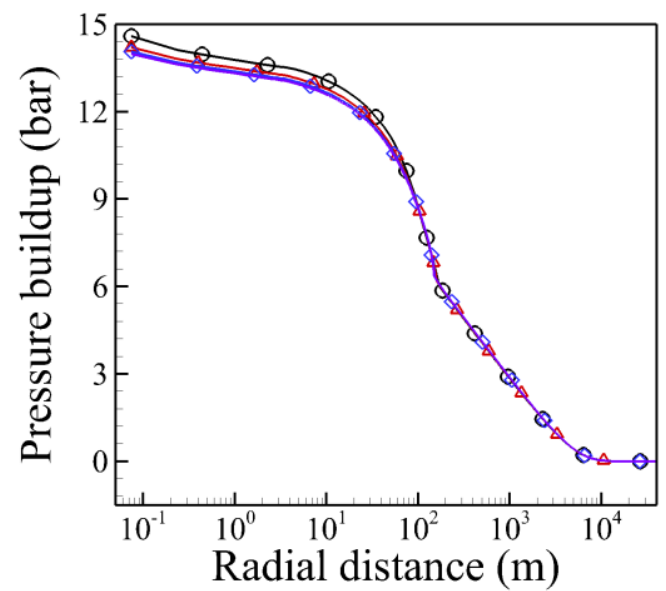

(a)

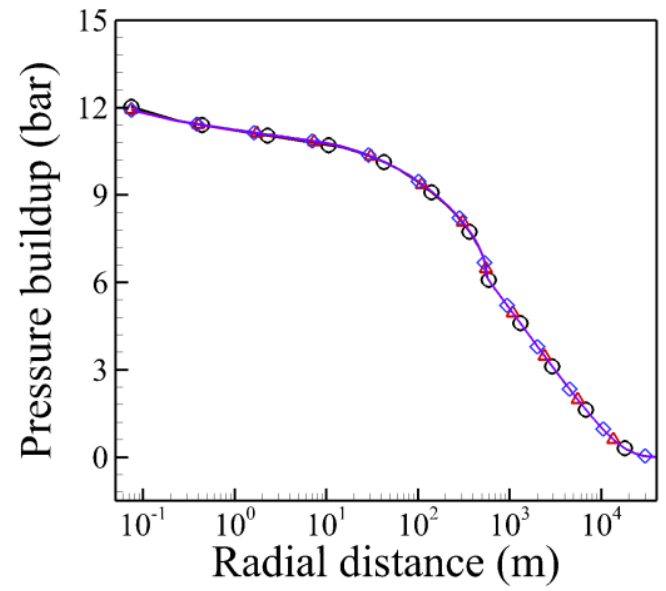

(c)

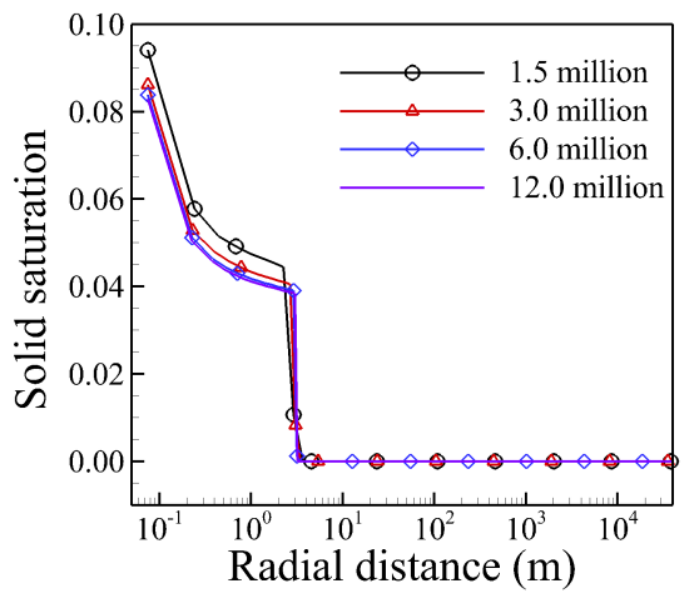

(b)

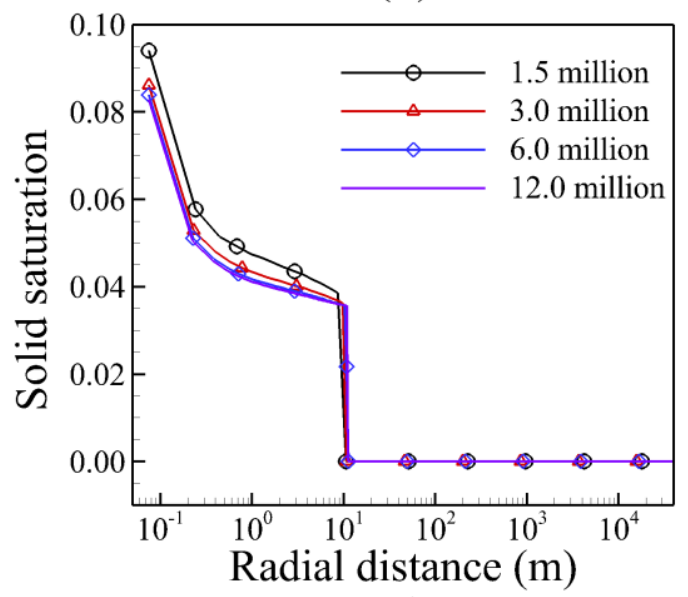

(d)

272 Fig. 5. The radial profiles of pressure buildup and solid saturation at the aquifer top for 10 days (top) and 100 days (bottom) for the grid dependence tests.

In this meshing system, the computation domain is discretized into 1000 grids in the radial

275 direction, 60 grids in the axial direction and 100 grids in the vertical direction. The grid size increases logarithmically from the injection well, with the finest grid located close to the

277 wellbore and the coarsest at the far side boundary in the radial direction. Every circle of the

278 mesh in the axial direction is divided uniformly, and the targeted formation is also divided

279 uniformly in the vertical direction. Similar meshing methods for the open and semi-closed

280 systems are adopted, except that the target formation for the semi-closed system is divided into

281220 grid blocks in the vertical direction. 


\section{Results and discussion}

3.1 The results of the closed system

The snapshots shown in Fig. 6 correspond to the cross sections of pressure buildup and gas

285 saturation at the end of the 30-year injection period. When large volumes of $\mathrm{CO}_{2}$ are injected into this system, a significant pressure buildup is produced. The range of pressure perturbation covers the whole domain, with an elevated pressure of 31.5 bars near the injection well and of 26.0 bars at the lateral boundary shown in Fig. 6(a). The radius of $\mathrm{CO}_{2}$ plume region is about 6

$289 \mathrm{~km}$ and the plume is concentrated at the top portion of the aquifer, as shown in Fig. 6(c). It is 290 clear that the scale of elevated pressure is much larger than the $\mathrm{CO}_{2}$ plume size. The contour 291 lines of pressure buildup in the $\mathrm{CO}_{2}$ plume region shown in Fig. 6(b) are inclined, caused by the 292 buoyancy and nonlinearity inherent in the two-phase flow system [3]. Meanwhile the contour 293 lines away from the $\mathrm{CO}_{2}$ plume region are mostly vertical, indicating a horizontal brine 294 displacement. 


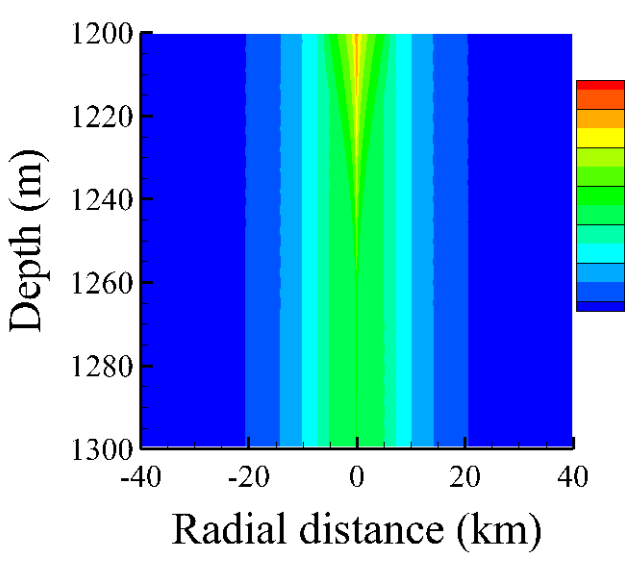

(a)

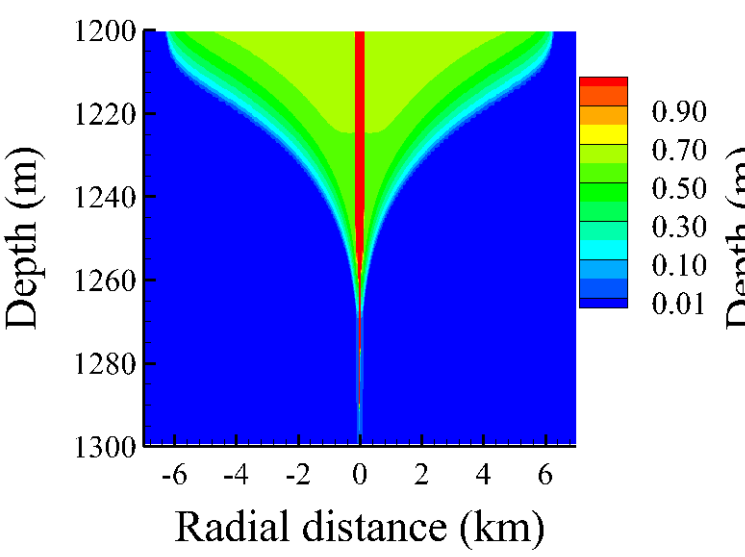

(c)

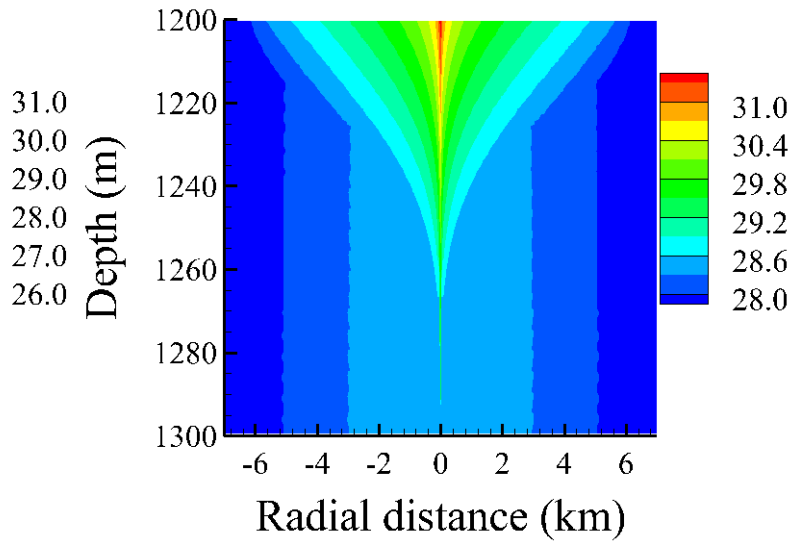

(b)

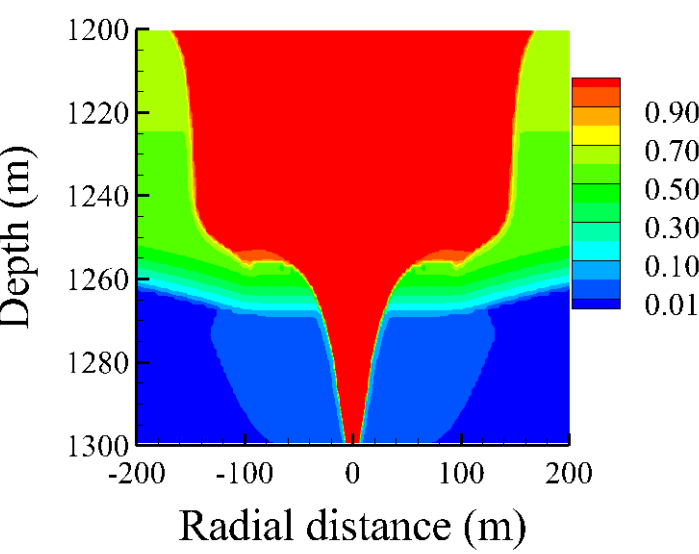

(d)

296 Fig. 6. Cross sections of pressure buildup (top: (b) is a zoom-in of (a)) and gas saturation (bottom: (d) is the zoom-in of (c)) for the closed system at 30 years of $\mathrm{CO}_{2}$ injection; pressure unit: bar.

299 Due to the evaporation of dry gas, salt precipitation occurs near the well. In order to better capture the dynamic behaviours of precipitation, the horizontal grid size is set to be $0.15 \mathrm{~m}$ near

301 the well, and increases logarithmically from the injection well. For the domain shown in Fig. 7,

302 in which salt precipitation takes place, there are 257 grids along the horizontal direction. The

303 precipitation distribution is controlled by the buoyancy driven $\mathrm{CO}_{2}$ plume, which presents two

304 kinds of precipitation, i.e., non-localized salt precipitation with smaller values and localized

305 salt precipitation with larger values (shown in the closed-up view). Compared with the contour 
map of gas saturation near the well in Fig. 6(d), the non-localized precipitation occurs inside the

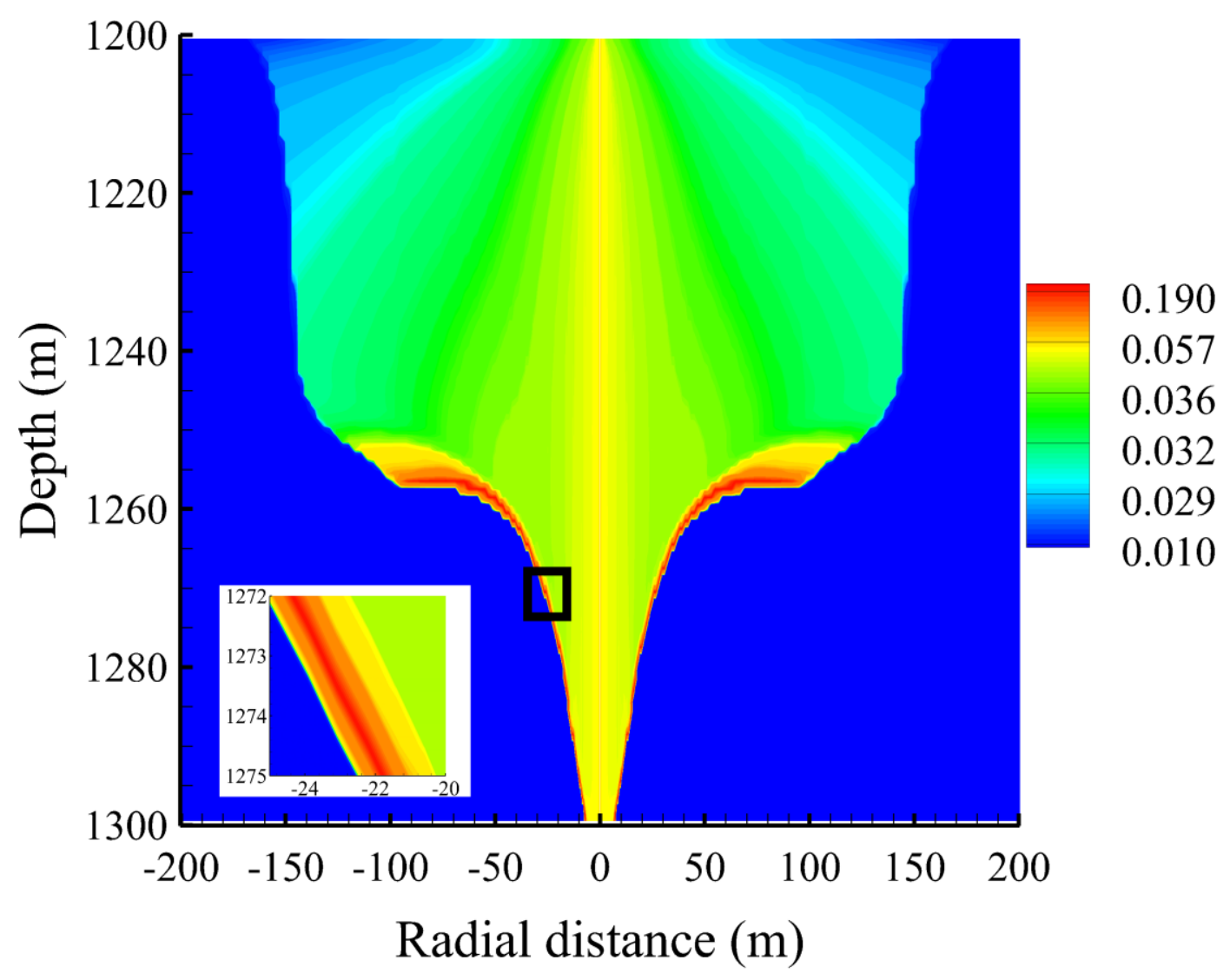

311 Fig. 7. Cross sections of solid saturation for the closed system at 30 years of $\mathrm{CO}_{2}$ injection with a close-up view of non-localized precipitation.

313 The solid saturation iso-surfaces at different time instants are shown in Fig. 8, where the 3D

314 results are shown for a three-quarter of the computational domain. The precipitation begins

315 from the injection well and develops with time. Different zones of solid saturation present 316 different behaviours with time, that is to say, the upper zone evolves continuously, while the 


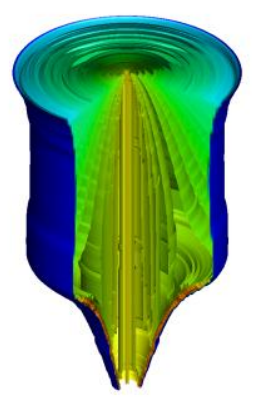

(a)

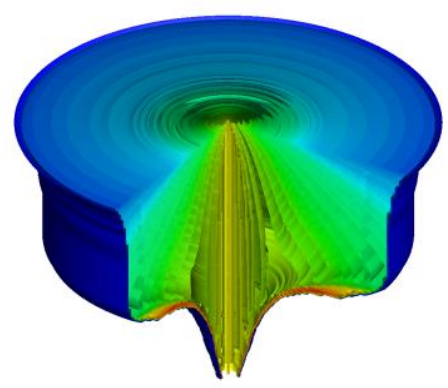

(c)
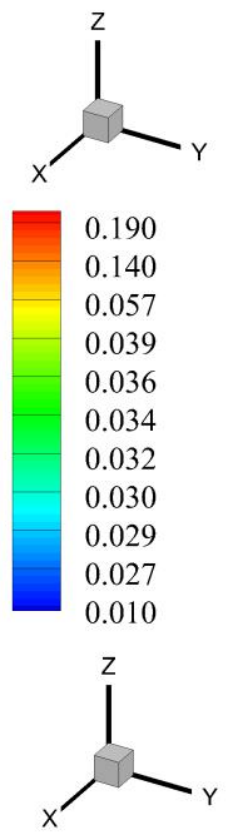

0.190

0.140

0.057

0.039

0.036

0.034

0.032

0.030

0.029

0.027

0.010

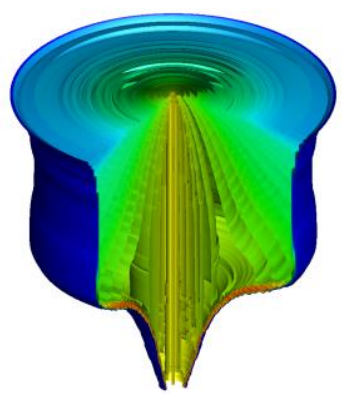

(b)

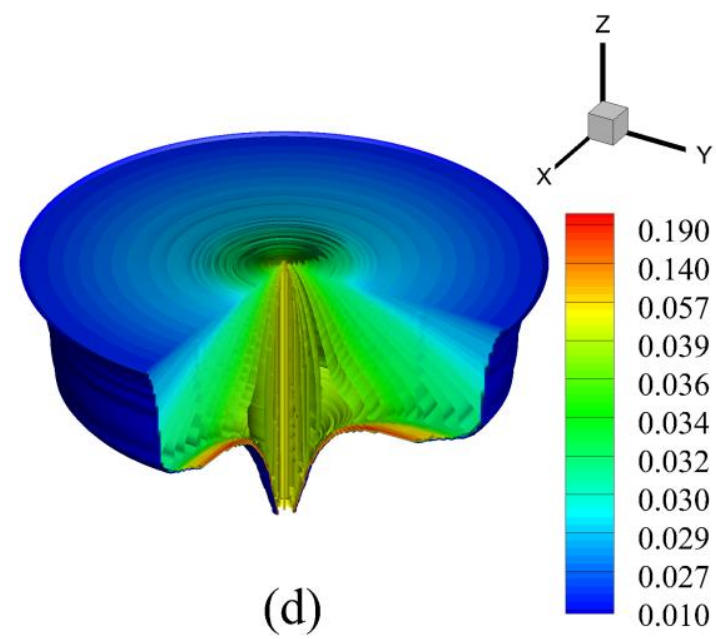

319 Fig. 8. Instantaneous iso-surfaces of solid saturation for the 3D closed system at different time instants.

Fig. 9 shows the temporal evolution of gas saturation and solid saturation, to illustrate the processes of the two types of precipitation. At the early stage, the injected $\mathrm{CO}_{2}$ mainly displaces the resident brine, accompanied by interphase mass transfer of both $\mathrm{CO}_{2}$ and brine between the aqueous phase and gas phase. When the brine becomes fully saturated due to the evaporation, the salt can quickly precipitate, corresponding to the quick increase of solid saturation. These trends for the two variables stop for the non-localized precipitation in Fig. 9(a). However, these trends still continue for the localized precipitation in Fig. 9(b). The capillary pressure 


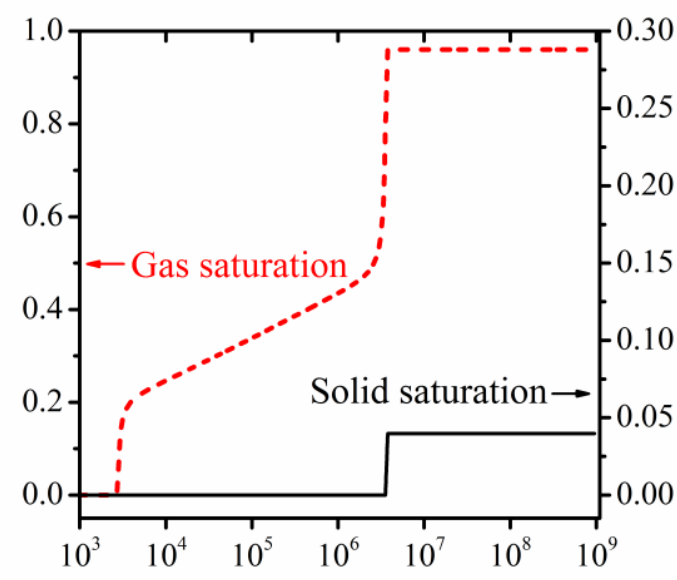

(a)

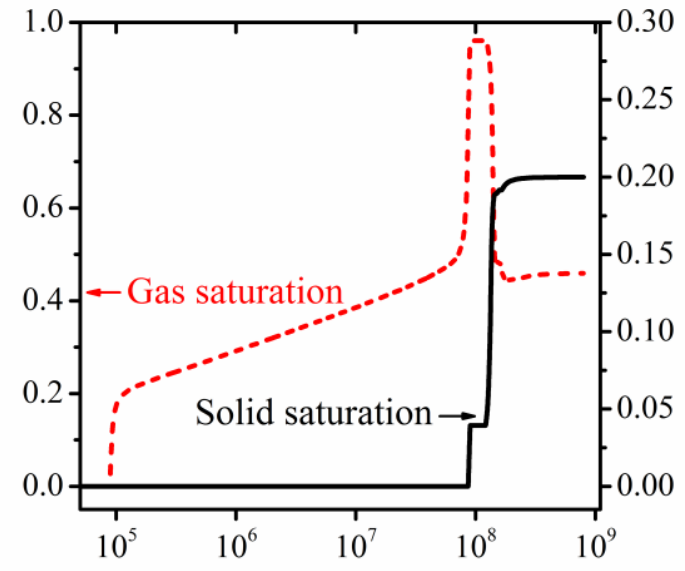

(b)

334 Fig. 9. The temporal evolution of gas saturation and solid saturation in (a) the non-localized precipitation region, (b) the localized precipitation region.

The pressure buildup along the bottom aquifer in Fig. 10(a) shows complicated behaviours.

337 Simulation results predict an initial jump followed by a quick decline and then a gradual

338 increase in near wellbore pressure over time. The pressure at these locations away from the

339 injection well increases monotonously with time. Most notably, the curves demonstrate a

340 pressure jump in the position of $8 \mathrm{~m}$ after an injection period of five years, and the values of

341 pressure jump increase with the injection time, as marked by the green circles in Fig. 10(a). The

342 differences of pressure are 0.38 bar for 5 years, 0.50 bar for 10 years, 0.70 bar for 20 years, and

343 0.89 bar for 30 years, which show an approximately linear behaviour. 

stage (less than 100 days), the solid saturation zone spreads with time. As the brine is displaced

346 gradually by the injected $\mathrm{CO}_{2}$, the amount of precipitable salt declines with the increasing

347 distance from the injection well, which in turn leads to the decrease of solid saturation. After 1

348 year injection, the backflow of brine occurs, resulting in a sharp gradient of solid saturation.

349 Compared with the results in Fig. 10(a), the location of the gradient of solid saturation

350 corresponds to the location of pressure jump. When the solid saturation amounts to 0.20 , the

351 pores are clogged completely and the horizontal flows of gas and aqueous phase are suppressed.

352 During the subsequent stages, the profiles of gas and solid saturations remain unchanged.

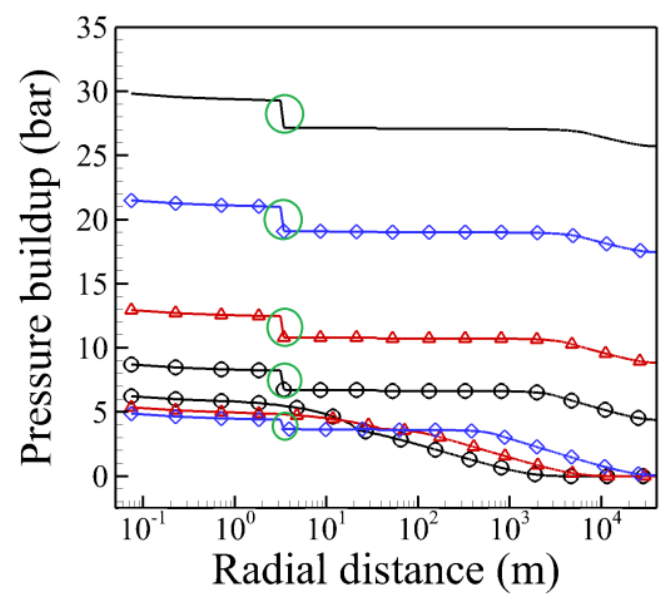

(a)

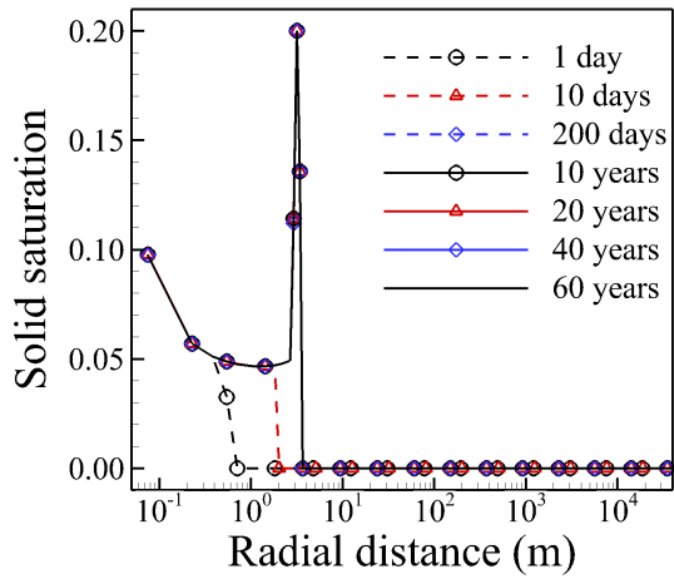

(b)

354 Fig. 10. Profiles along the bottom of the aquifer for the closed system at different injection time instants for (a) pressure buildup and (b) solid saturation.

The results of lower injection rate of $50 \mathrm{~kg} / \mathrm{s}$ with the same total amount of $\mathrm{CO}_{2}$ are given in

357 Fig. 11-12. The values of hydrogeological parameters used in this model are given in Tab 1.

Fig. 11 shows the cross sections of gas and solid saturations with injection rate of $50 \mathrm{~kg} / \mathrm{s}$ at the end of the injection period of 60 years. Compared with the larger injection rate case, there 
are obvious differences in the shapes of these distributions. The horizontal spread of the gas

361 phase is reduced while the vertical movement is enhanced. Similar to the larger-rate case, the

362 solid salt appears in the zone of single gas phase. Rather different precipitation behaviours are

363 observed at the lower rate. The distribution radii of solid precipitation zone are smaller near the

364 lower portions of the well, while the radii are larger near the upper portions of the well. The

365 accumulation of solids in this case exacerbates gravity override effect, which means that more

366 gas phase accumulates at the top aquifer. The distribution of gas phase increases the risk of

367 leakage and reduces the security of $\mathrm{CO}_{2}$ storage. The narrower zone at the bottom of the aquifer

368 attenuates the pressure jump, which can be clearly seen in Fig. 12(a).

369

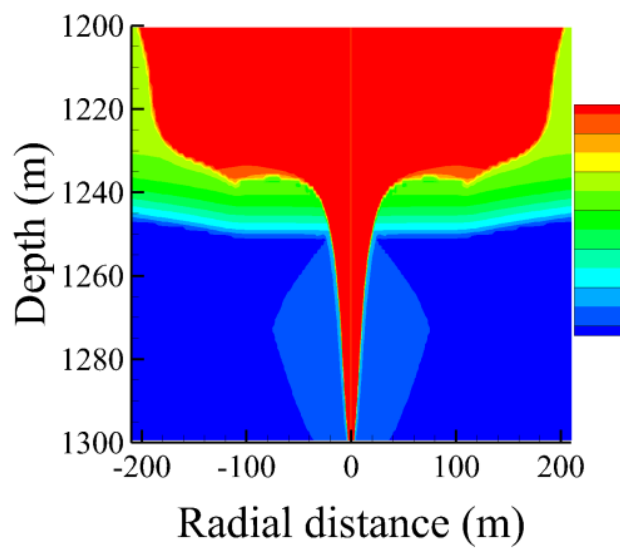

(a)

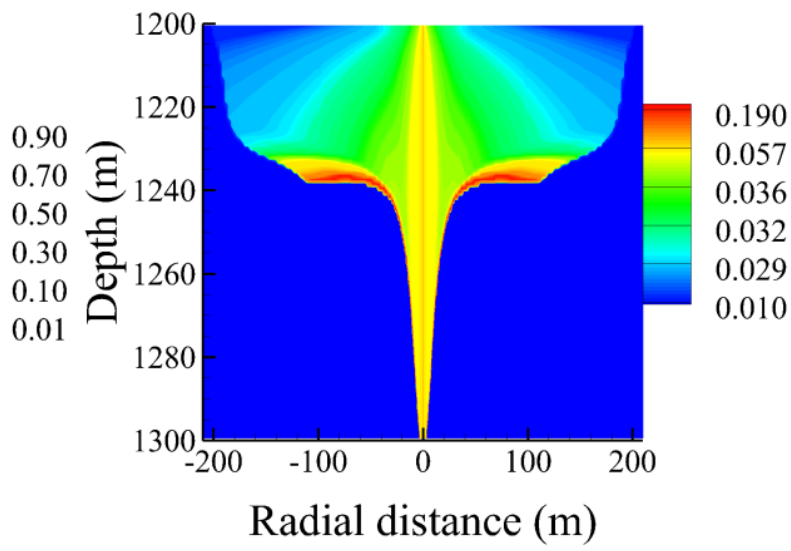

(b)

Fig. 11. Spatial distributions for the closed system at 60 years of $\mathrm{CO}_{2}$ injection of (a) gas saturation and (b) solid saturation.

Fig. 12 shows the cross sections of pressure buildup and solid saturation at different time instants. Compared with the larger-rate case, the increment of pressure is slightly lower, while the values of pressure jump are higher at the bottom of the aquifer, as marked by the green circles in Fig. 12(a). The differences of pressure are 0.73 bar for 200 days, 1.50 bars for 10 years, 1.66 bars for 20 years, 1.94 bars for 40 years, and 2.15 bars for 60 years, respectively. The value 
378 10(b). The distance between the impervious barrier and the wellbore is shorter, which is only

$3793.2 \mathrm{~m}$. All of these factors could increase the possibility of fracture near the lower portion of

380 injection well.

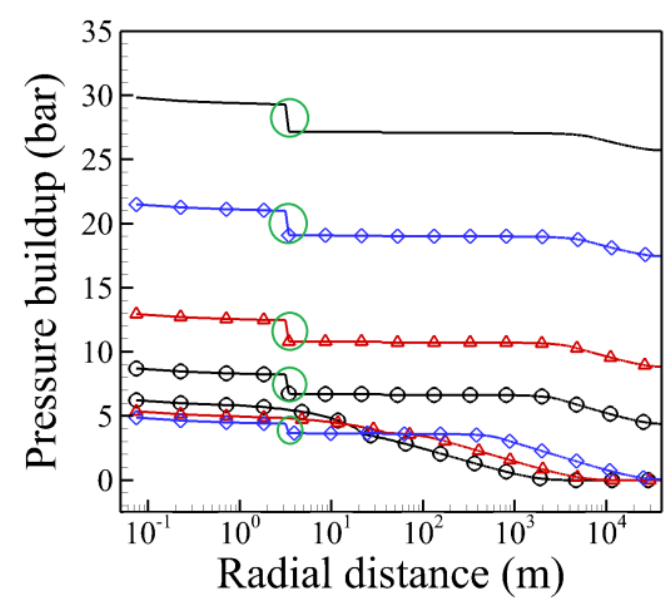

(a)

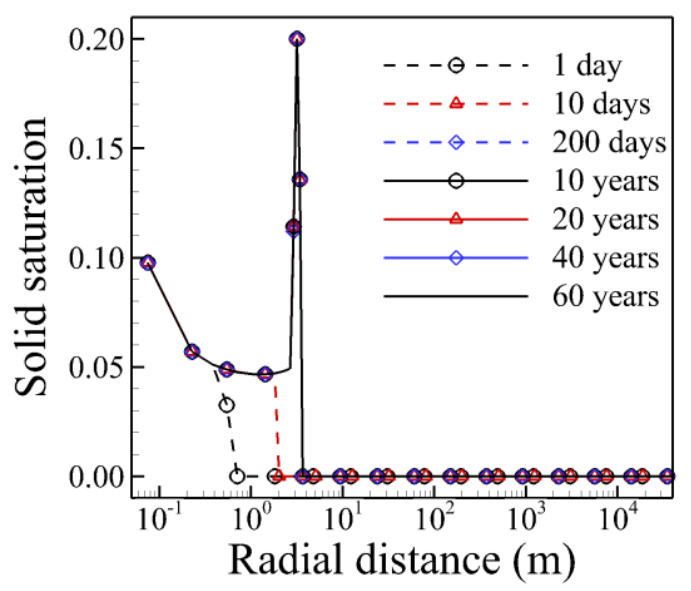

(b)

382 Fig. 12. Profiles along the bottom of the aquifer for the closed system with injection rate of 50 $\mathrm{kg} / \mathrm{s}$ at different injection time instants for (a) pressure buildup, and (b) solid saturation.

\subsection{The results of the open system} solid saturations for the open system at the end of the 30-year injection period. Compared with the results in the closed system, a significant difference in the contour maps of pressure buildup is observed. The values of pressure buildup are lower, with maximum value of 9.5 bars at the top of the injection well. In marked contrast to the difference in the distribution of pressure buildup, minor differences in the $\mathrm{CO}_{2}$ plumes and solid saturation distributions are observed. Comparison of the results in the closed and open systems indicates that the shapes of gas and solid phase distributions for the two storage systems are generally similar, with a larger distance 
caused by the differences in pressure buildup.

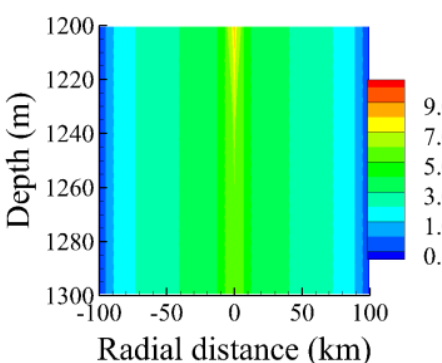

(a)

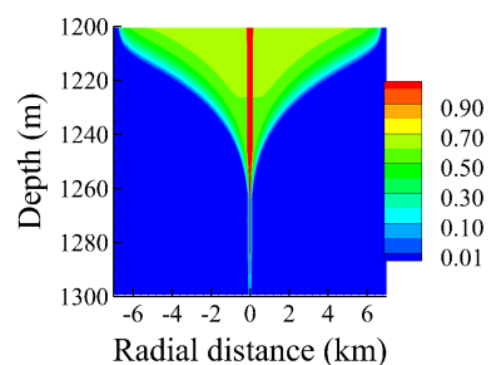

(b)

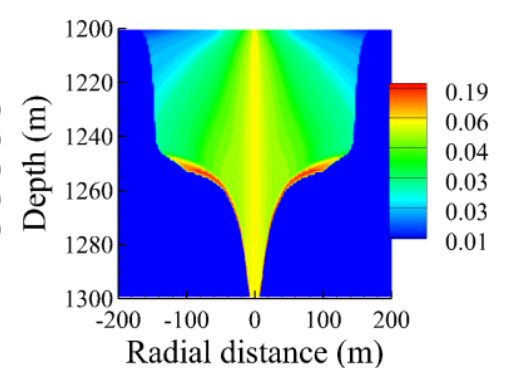

(c)

396 Fig. 13. Cross sections of (a) pressure buildup (unit: bar), (b) gas saturation and (c) solid saturation for the open system at 30 years of $\mathrm{CO}_{2}$ injection.

Fig. 14 shows the radial profiles of pressure buildup and solid saturation at the same time instants as the closed system throughout the injection period. The profiles of pressure buildup show different behaviours compared with those in Fig. 10. Simulation results predict an initial jump followed by the continuous decline in the pressure near wellbore over time, while the pressures in the other region increase slightly. As the outflow rates of brine at the lateral

403 boundaries are constant, the pressure changes in the whole domain are not obvious. Meanwhile,

404 the pressure profiles along the bottom aquifer also present a jump near the well due to the localized precipitation. The radial profiles of solid saturation in the closed and open systems are

406 generally similar, with minor differences in the radial distance of solid saturation along the 407 bottom surface of the aquifer. 


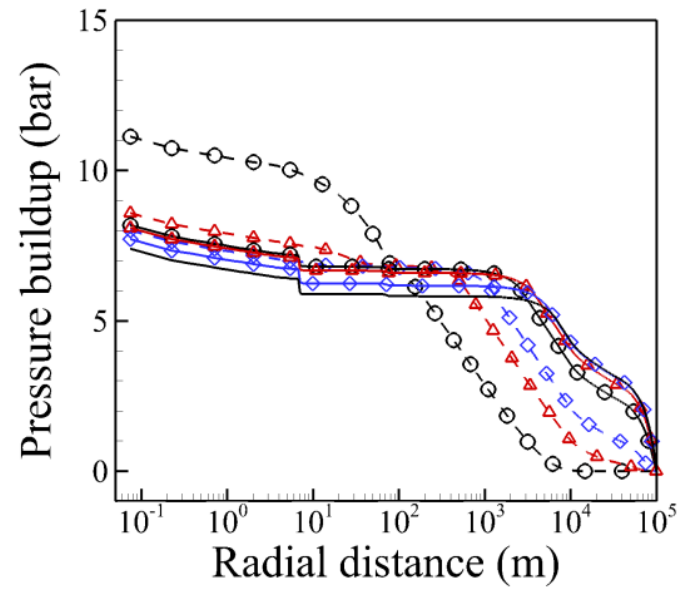

(a)

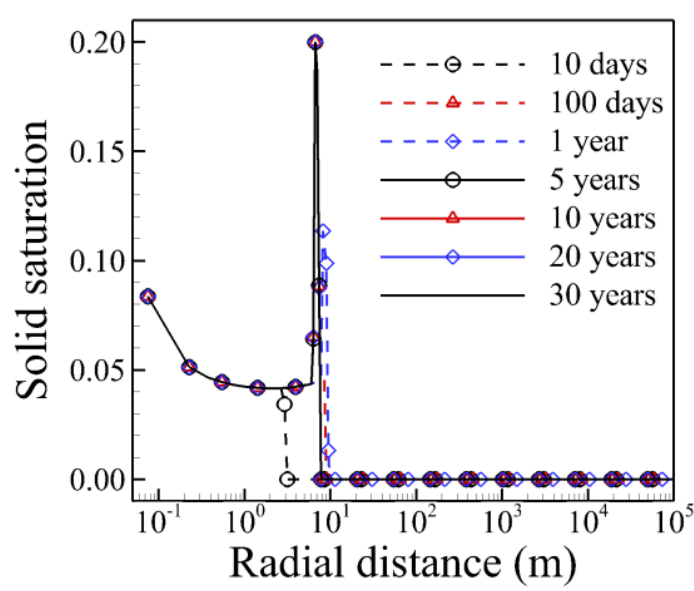

(b)

409 Fig. 14. Profiles along the bottom of the aquifer for the open system at different injection time instants for (a) pressure buildup (unit: bar), and (b) solid saturation.

\subsection{The results of the semi-closed system}

Fig. 15 shows the cross sections of pressure buildup with seal permeabilities of $10^{-17} \mathrm{~m}^{2}, 10^{-18}$

$413 \mathrm{~m}^{2}$ and $10^{-19} \mathrm{~m}^{2}$ at the end of the 30 -year injection period. In these cases, a small fraction of the brine in the storage formation is displaced into the overlying and underlying formations during the injection period, which can provide additional storage space for $\mathrm{CO}_{2}$. Hence less pressure buildup occurs in the semi-closed system compared with the results in Fig. 6(a). The pressure

417 buildup in the storage formations is very sensitive to the seal permeability. In the lowest seal

418 permeability $\left(10^{-19} \mathrm{~m}^{2}\right)$ case, the pressure buildup shows similar behaviours to those in the

419 closed system. The propagation of elevated pressure is mainly in the storage formation. The

420 values of pressure buildup in the storage formations are much higher than the values in the seal

421 formations. In the medium seal permeability $\left(10^{-18} \mathrm{~m}^{2}\right)$ case, the elevated pressure in the storage saline is lower than that in the lowest seal permeability case. More native brine in the storage formation is discharged into the seal formations. In the largest seal permeability $\left(10^{-17} \mathrm{~m}^{2}\right)$ case,

424 the propagation of elevated pressure is dominant in the vertical direction. With the increase of 


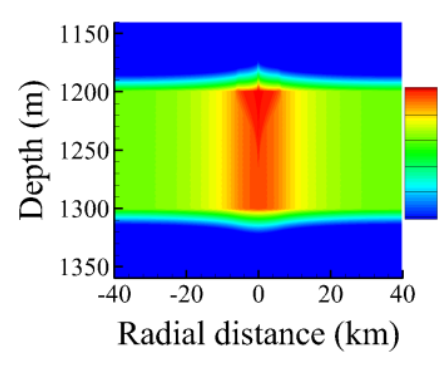

(a)

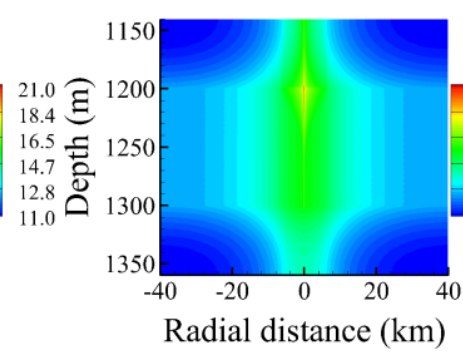

(b)

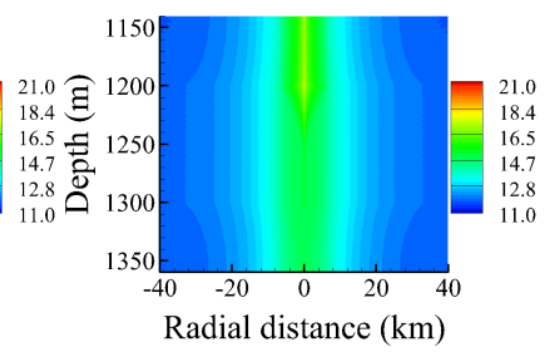

(c)

Fig. 15. Cross sections of pressure buildup (unit: bar) with seal permeabilities of (a) $10^{-19} \mathrm{~m}^{2}$, (b) $10^{-18} \mathrm{~m}^{2}$, and (c) $10^{-17} \mathrm{~m}^{2}$ for the semi-closed system.

Fig. 16 shows the cross sections of solid saturation with three different seal permeabilities, where (a2-c2) are the zoom-in graphs of (a1-c1). In contrast to the distribution of pressure buildup, the solid saturation is less sensitive to the seal permeability. Comparison of Fig. 16 (a1-c1) indicates that the contour maps of solid precipitation in all the semi-closed cases are generally similar in shape, with several minor differences at the top of the storage formations. In addition to the two types of precipitation near the injection well (i.e., non-localized salt

438 precipitation of smaller values, localized salt precipitation of larger values), the third type of

439 solid precipitation occurs at the interfaces between the storage formation and the seal

440 formations. At the interfaces, injected $\mathrm{CO}_{2}$ in the storage saline hardly enters into the seal

441 formations, which needs to overcome a considerable capillary entry pressure. Consequently, the

442 flow of single gas phase at the interfaces can be suppressed and thus more salt can precipitate at

443 these locations. With the increase of seal permeability, both the thickness of this kind of 
445 precipitation zones at the interfaces contribute to reducing the leakage rate of gas phase from 446 the storage saline into the seal formations.

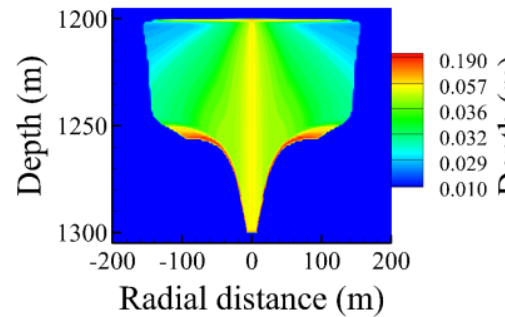

(a1)

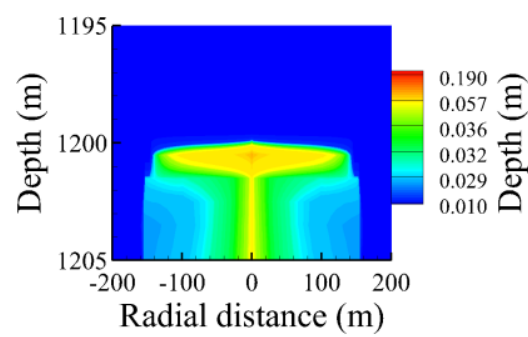

(a2)

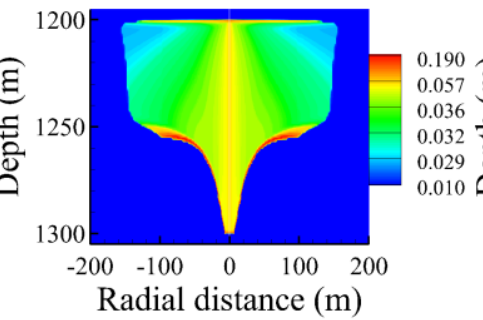

(b1)

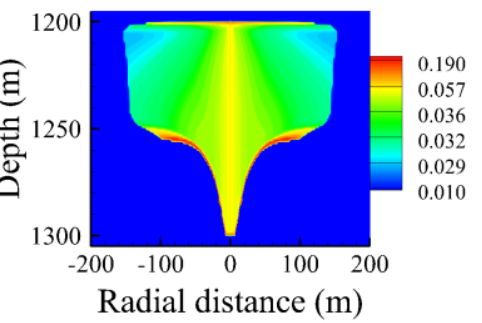

(c1) period. The profiles of pressure buildup show similar behaviours to those of the closed system. Due to the leakage of brine into the seal formations, the values of pressure buildup at the top and bottom aquifer are lower. The pressure profiles along the bottom aquifer also show a jump near the wellbore. The values of salt saturation near the well increase during the whole injection period, which are different from those in the closed and open storage systems. Due to the lower seal permeability and the capillary pressure, the injected $\mathrm{CO}_{2}$ hardly enters into the seal 
brine at the interfaces continuously, which leads to the increase of solid saturation.

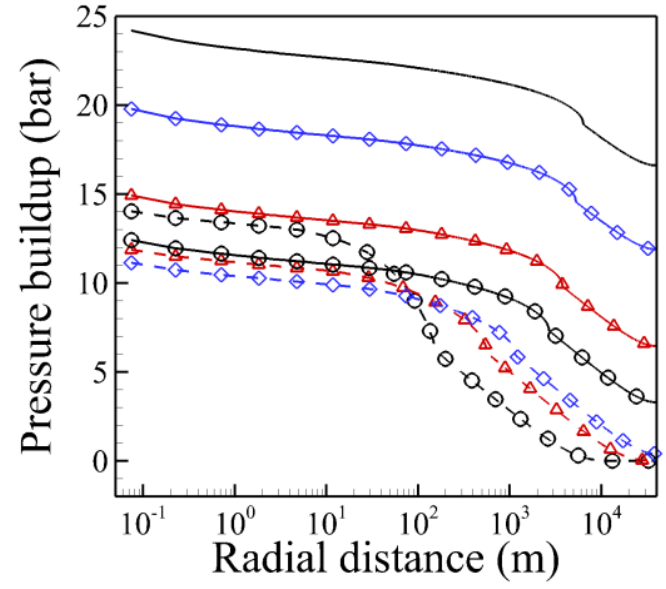

(a)

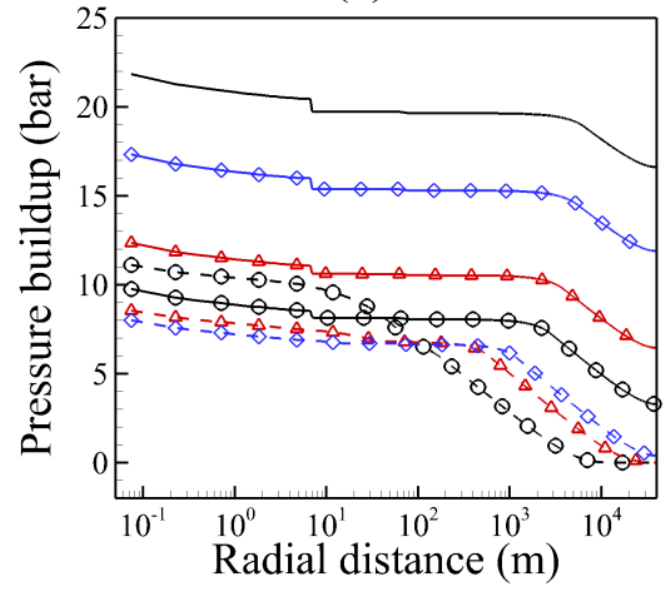

(c)

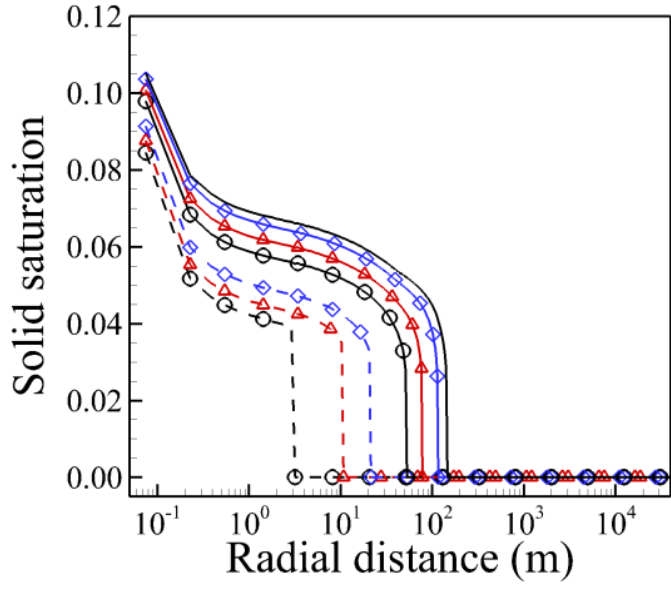

(b)

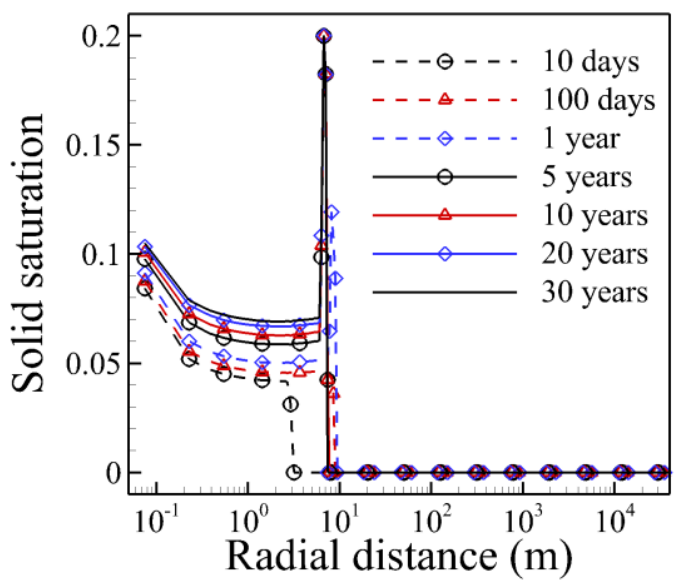

(d)

461 Fig. 17. Profiles of (a, c) pressure buildup (unit: bar)and (b, d) solid saturation for the semi-closed system along (a-b) the top and (c-d) the bottom of the aquifer with seal permeability of $10^{-19} \mathrm{~m}^{2}$ at different injection time instants.

\section{Conclusions}

Numerical simulations have been carried out for a better understanding of the phenomena of pressure buildup and salt precipitation during $\mathrm{CO}_{2}$ injection period for carbon storage. In order to understand the effects of boundary conditions on $\mathrm{CO}_{2}$ storage, three storage systems with different boundary conditions have been numerically simulated and compared. This study also 
evaluates the flow of gas phase and the propagation of pressure, taking into account the effect of

470 precipitation. The main conclusions from the numerical simulations are given as follows:

(1) It has been shown that the region of elevated pressure is much larger than the $\mathrm{CO}_{2}$ plume size, while the salt precipitation due to the evaporation of gas phase only occurs in the small zone of single gas phase. contour maps of solid saturation with the same injection rate for the three storage systems are generally similar in shape, with several small differences in precipitation zone observed for the three systems.

(3) There are two types of precipitation formed near the well, i.e., non-localized precipitation near the injection well and localized precipitation in the lower portion of the dry-out front. The evaporation of gas phase leads to precipitation near the well and the backflow of brine due to

481 capillary pressure results in the impervious zone near the lower portion of the well. The

482 formation processes of the two types of precipitation are different, which go through different 483 periods. For the semi-closed system, in addition to the two types of precipitation, a third type of 484 solid precipitation forms at the interfaces between the storage and seal formations. The salt 485 precipitation leads to the decrease of porosity and permeability and thus the degradation of 486 injectivity.

487 (4) The precipitation can affect the transportation of the gas phase and the propagation of 488 pressure. The localized precipitation acts as a barrier that suppresses the horizontal flow of gas 489 phase and promotes the upward flow of injected $\mathrm{CO}_{2}$. The pressure profiles are smooth during 
the early stage, while the curves reveal distinct gradients when the pores at the bottom aquifer

491 are clogged completely. It can be concluded that the injection rate is important for the salt

492 precipitation process. For the lower injection rate, more backflow of the brine occurs, leading to

493 more gas phase accumulating at the aquifer top, a narrower space for the gas phase flow and a

494 higher pressure jump at the bottom aquifer. The localized precipitation increases the risk of

495 leakage and reduces the security of $\mathrm{CO}_{2}$ storage.

496 In the present study, the salt precipitation is treated as an immobile phase that clogs the pores.

497 In reality, the transportation of solid salt, from one location to another, can largely follow the

498 movement of fluids such as liquids and gases. However, the flow of precipitation is very

499 complicated and constitutive relations would be needed to specify the motion. In the future, a

500 more sophisticated model for the movement of solid precipitation will be considered. Moreover,

501 in order to effectively capture the dynamic behaviours of pressure buildup and salt precipitation

502 in full-scale carbon storage, sub-grid scale dynamics may be modelled using an upscaling

503 approach of the physical problem in a given time scale, which is being carried out. 
References

507 [1] Bachu S. $\mathrm{CO}_{2}$ storage in geological media: role, means, status and barriers to deployment.

$508 \quad$ Prog Energy Combust Sci 2008;34:254-73.

509 [2] Metz B, Davidson O, de Coninck H, Loos M, Meyer L. IPCC special report on carbon 510 dioxide capture and storage. Cambridge University Press, Cambridge, United Kingdom

$511 \quad$ and New York, USA; 2005.

512 [3] Jiang X. A review of physical modelling and numerical simulation of long-term geological storage of $\mathrm{CO}_{2}$. Appl Energy 2011;88:3557-66.

514 [4] Mathias S, González Martínez de Miguel G, Thatcher K, Zimmerman R. Pressure buildup during $\mathrm{CO}_{2}$ injection into a closed brine aquifer. Transp Porous Med 2011;89:383-97.

516 [5] Yamamoto H, Zhang K, Karasaki K, Marui A, Uehara H, Nishikawa N. Numerical investigation concerning the impact of $\mathrm{CO}_{2}$ geologic storage on regional groundwater

$518 \quad$ flow. Int J Greenh Gas Con 2009;3:586-99.

519 [6] Zhou Q, Birkholzer JT, Tsang C-F, Rutqvist J. A method for quick assessment of $\mathrm{CO}_{2}$ storage capacity in closed and semi-closed saline formations. Int J Greenh Gas Con 2008;2:626-39.

[7] Pruess K, Müller N. Formation dry-out from $\mathrm{CO}_{2}$ injection into saline aquifers: 1 . Effects of solids precipitation and their mitigation. Water Resour Res 2009;45:W03402.

524 [8] Kim KY, Han WS, Oh J, Kim T, Kim JC. Characteristics of salt-precipitation and the 

2012;92:397-418.

527 [9] Mathias SA, Gluyas JG, González Martínez de Miguel GJ, Hosseini SA. Role of partial miscibility on pressure buildup due to constant rate injection of $\mathrm{CO}_{2}$ into closed and open brine aquifers Water Resour Res. 2011;47:W12525.

[10] Zeidouni M, Pooladi-Darvish M, Keith D. Analytical solution to evaluate salt precipitation during $\mathrm{CO}_{2}$ injection in saline aquifers. Int J Greenh Gas Con 2009;3:600-11.

[11] Pruess K. Formation dry-out from $\mathrm{CO}_{2}$ injection into saline aquifers: 2. Analytical model for salt precipitation. Water Resour Res 2009;45:W03403.

534 [12] Muller N, Qi R, Mackie E, Pruess K, Blunt $\mathrm{MJ}^{\mathrm{CO}_{2}}$ injection impairment due to halite precipitation. Energy Procedia 2009;1:3507-14.

[13] Mahadevan J, Sharma M, Yortsos Y. Water removal from porous media by gas injection: experiments and simulation. Transp Porous Med 2007;66:287-309.

538 [14] Giorgis T, Carpita M, Battistelli A. 2D modeling of salt precipitation during the injection of dry $\mathrm{CO}_{2}$ in a depleted gas reservoir. Energy Convers Manag 2007;48(6):1816-26.

540 [15] Zhou Q, Birkholzer JT. On scale and magnitude of pressure build-up induced by

541 large-scale geologic storage of $\mathrm{CO}_{2}$. Greenh Gases: Sci Technol 2011;1:11-20.

542 [16] Pau GSH, Bell JB, Pruess K, Almgren AS, Lijewski MJ, Zhang KN. High-resolution 543 simulation and characterization of density-driven flow in $\mathrm{CO}_{2}$ storage in saline aquifers. $544 \quad$ Adv Water Resour 2010;33:443-55. 
545 [17] Birkholzer JT, Zhou Q, Tsang C-F. Large-scale impact of $\mathrm{CO}_{2}$ storage in deep saline 546 aquifers: A sensitivity study on pressure response in stratified systems. Int J Greenh Gas $547 \quad$ Con 2009;3:181-94.

548 [18] Cihan A, Birkholzer JT, Zhou Q. Pressure buildup and brine migration during $\mathrm{CO}_{2}$ storage in multilayered aquifers. Ground Water 2012;51:1-16.

550 [19] Saripalli P, McGrail P. Semi-analytical approaches to modeling deep well injection of $\mathrm{CO}_{2}$

[20] Nordbotten JM, Celia MA, Bachu S. Similarity solutions for fluid injection into confined aquifers. J Fluid Mech 2006;561:307-27.

554 [21] Nordbotten JM, Celia MA, Bachu S. Injection and storage of $\mathrm{CO}_{2}$ in deep saline aquifers:

555 Analytical solution for $\mathrm{CO}_{2}$ plume evolution during injection. Transp Porous Med 2005;58:339-60.

557 [22] Okwen RT, Stewart MT, Cunningham JA. Temporal variations in near-wellbore pressures during $\mathrm{CO}_{2}$ injection in saline aquifers. Int J Greenh Gas Con 2011;5:1140-8.

[23] Nicot JP. Evaluation of large-scale $\mathrm{CO}_{2}$ storage on fresh-water sections of aquifers: An example from the Texas Gulf Coast Basin. Int J Greenh Gas Con 2008;2:582-93.

561 [24] Birkholzer JT, Zhou Q, Tsang CF. Large-scale impact of $\mathrm{CO}_{2}$ storage in deep saline aquifers: A sensitivity study on pressure response in stratified systems. Int J Greenh Gas Con 2009;3:181-94.

564 [25] Environment Protection Agency. Federal requirements under the underground injection control (UIC) program for carbon dioxide $\left(\mathrm{CO}_{2}\right)$ geological sequestration (GS) wells; 
proposed rule; 2008.

567 [26] Rutqvist J, Birkholzer JT, Cappa F, Tsang CF. Estimating maximum sustainable injection pressure during geological sequestration of $\mathrm{CO}_{2}$ using coupled fluid flow and geomechanical fault-slip analysis. Energy Convers and Manag 2007;48:1798-807.

[27] Rutqvist J, Birkholzer JT, Tsang CF. Coupled reservoir-geomechanical analysis of the potential for tensile and shear failure associated with $\mathrm{CO}_{2}$ injection in multilayered reservoir-caprock systems. Int J Rock Mech Min Sci 2008;45:132-43.

573 [28] Zhang Z, Agarwal R. Numerical simulation and optimization of $\mathrm{CO}_{2}$ sequestration in saline aquifers. Comput Fluids 2013;80:79-87.

575 [29] Wan LJ, Li KL, Liu J, Li KQ. GPU implementation of a parallel two-list algorithm for the subset-sum problem. Concurrency Computat: Pract Exper 2015; 27:119-145.

577 [30] Yang WD, Li KL, Liu Y, Shi L, Wan LJ. Optimization of quasi-diagonal matrix-vector multiplication on GPU. Int J High Perform C 2014;28(2):183-195.

579 [31] Jie L, Li KL, Shi L, Liu RS, Mei J. Accelerating solidification process simulation for large-sized system of liquid metal atoms using GPU with CUDA. J Comput Physics 2014; 257: 521-535.

582 [32] Wang YX, Zhang LL, Liu W, Che YG, Xu CF, Wang ZH, Zhuang Y. Efficient parallel implementation of large scale 3D structured grid CFD applications on the Tianhe-1A supercomputer. Comput Fluids 2013;80:244-250.

585 [33] Peysson Y, Bazin B, Magnier C, Kohler E, Youssef S. Permeability alteration due to salt precipitation driven by drying in the context of $\mathrm{CO}_{2}$ injection. Energy Procedia 
588 [34] Kim M, Sell A, Sinton D. Aquifer-on-a-Chip: understanding pore-scale salt precipitation dynamics during $\mathrm{CO}_{2}$ sequestration. Lab Chip 2013;13:2508-18.

590 [35] Hurter S, Berge J, Labregere D. Simulations for $\mathrm{CO}_{2}$ injection projects with compositional simulator. In: SPE 108540, Offshore Europe, Aberdeen, Scotland, UK; 2007.

592 [36] Piri M, Prévost JH, Fuller R. Carbon dioxide sequestration in saline aquifers: evaporation, 593 precipitation and compressibility effects. In: Fourth Annual Conference on Carbon 594 Capture and Sequestration; 2-5 May, Alexandra Virginia; 2005.

595 [37] Prévost JH, Fuller R, Altevogt AS, Bruant R, Scherer GW. Numerical modeling of carbon 596 dioxide injection and transport in deep saline aquifers. In: Proceedings, 7th International 597 Conference on Greenhouse Gas Control Technologies, Vancouver, BC, vol II (2), Poster 598 Papers Elsevier Ltd; 2004.

599 [38] Helmig R. Multiphase flow and transport processes in the subsurface: a contribution to the modeling of hydrosystems. Berlin: Springer; 1997.

601 [39] Bear J. Dynamics of fluids in porous media. New York: McGraw-Hill; 1972.

602 [40] Van Genuchten MT. A closed-form equation for predicting the hydraulic conductivity of unsaturated soils. Soil Sci Soc Am J 1980;44:892-8.

604 [41] Corey AT. The interrelation between gas and oil relative permeabilities. Prod 605 Mon.1954;19:38-41.

606 [42] Spycher N, Pruess K. $\mathrm{CO}_{2}-\mathrm{H}_{2} \mathrm{O}$ mixtures in the geological sequestration of $\mathrm{CO}_{2}$. II. 
607 Partitioning in chloride brines at $12-100^{\circ} \mathrm{C}$ and up to 600 bar. Geochim Cosmochim Acta

$608 \quad 2005 ; 69: 3309-20$.

609 [43] Nelson PH. Permeability-porosity relationships In sedimentary rocks. The Log Analyst $610 \quad 1994 ; 35: 38-62$.

611 [44] Verma A, Pruess K. Thermohydrological conditions and silica redistribution near

612 high-level nuclear wastes emplaced in saturated geological formations. J Geophys Res:

$613 \quad$ Solid Earth 1988;93:1159-73.

614 [45] Saad Y. Iterative methods for sparse linear systems. SIAM, Philadelphia, PA, second $615 \quad$ edition, 2003.

616 
619 Fig. 1. Schematic representation of (a) $\mathrm{CO}_{2}$ injection into a closed aquifer via a vertical well and (b) top view.

Fig. 2. Schematic representation of boundary conditions for the three storage systems: (a) open system, (b) closed system, and (c) semi-closed system.

623 Fig. 3. Spatial discretization considered in this study.

624 Fig. 4. A 16-meshes domain partitioning on 4 processors.

625 Fig. 5. The radial profiles of pressure buildup and solid saturation at the aquifer top for 10 days (top) and 100 days (bottom) for the grid dependence test.

Fig. 6. Cross sections of pressure buildup (top: (b) is a zoom-in of (a)) and gas saturation (bottom: (d) is the zoom-in of (c)) for the closed system at 30 years of $\mathrm{CO}_{2}$ injection;

Fig. 7. Cross sections of solid saturation for the closed system at 30 years of $\mathrm{CO}_{2}$ injection with a close-up view of non-localized precipitation.

Fig. 8. Instantaneous iso-surfaces of solid saturation for the $3 \mathrm{D}$ closed system at different time instants.

Fig. 9. The temporal evolution of gas saturation and solid saturation in (a) the non-localized precipitation region, (b) the localized precipitation region.

636 Fig. 10. Profiles along the bottom of the aquifer for the closed system at different injection time 

instants for (a) pressure buildup (unit: bar) and (b) solid saturation.

638 Fig. 11. Spatial distributions for the closed system at 60 years of $\mathrm{CO}_{2}$ injection of (a) gas saturation and (b) solid saturation.

640 Fig. 12. Profiles along the bottom of the aquifer for the closed system with injection rate of 50 $\mathrm{kg} / \mathrm{s}$ at different injection time instants for (a) pressure buildup (unit: bar), and (b) solid saturation.

643 Fig. 13. Cross sections of (a) pressure buildup (unit: bar), (b) gas saturation and (c) solid saturation for the open system at 30 years of $\mathrm{CO}_{2}$ injection.

645 Fig. 14. Profiles along the bottom of the aquifer for the open system at different injection time instants for (a) pressure buildup, and (b) solid saturation.

647 Fig. 15. Cross sections of pressure buildup (unit: bar) with seal permeabilities of (a) $10^{-19} \mathrm{~m}^{2}$, (b) $10^{-18} \mathrm{~m}^{2}$, and (c) $10^{-17} \mathrm{~m}^{2}$ for the semi-closed system.

649 Fig. 16. Cross sections of solid saturation with seal permeability of (a1, a2) $10^{-19} \mathrm{~m}^{2}$, (b1, b2) $10^{-18} \mathrm{~m}^{2}$, and $(\mathrm{c} 1, \mathrm{c} 2) 10^{-17} \mathrm{~m}^{2}$ for the semi-closed system.

651 Fig. 17. Profiles of (a, c) pressure buildup and (b, d) solid saturation for the semi-closed system along (a-b) the top and (c-d) the bottom of the aquifer with seal permeability of $10^{-19} \mathrm{~m}^{2}$ at different injection time instants. 


\section{Table Titles.}

656

657 Tab. 1. Hydrogeological properties of the storage formation.

658 Tab. 2. Example of domain partitioning and local numbering. 